\title{
Deconditioning persisting avoidance: Spacing counterconditioning periods during response prevention*
}

\author{
RODNEY S. BUSS and LARRY D. REID \\ Bradley Lniveristy. Peoria. Ill. 61606
}

Ten groups of rats were fixed with chronically indwelling electrodes for intracranial stimulation (ICS) of positive areas of the lateral hypothalamus. All were trained, with over 500 trials, to avoid footshock by climbing to a ledge. After training, footshock was terminated and response perseveration measured. Between training and testing for persistence of responding, a variety of treatments were programmed, including the delivery of ICS as a potential counterconditioner to the first, middle, and third parts of a response prevention period or throughout the period. After 500 training trials, rats receiving no treatment persisted in responding for hundreds of trials. Response prevention with limited ICS, regardless of how the ICS was distributed, did not reliably reduce responding compared to no treatment, but response prevention with frequent ICS throughout response prevention did. The results support the notion that counterconditioning therapies, e.g., desensitization, are preferable to response prevention therapies, e.g., implosion or flooding, or combinations of counterconditioning and implosion.

The determination of the most efficient ways to reduce persisting avoidance after discontinuation of the aversive stimulation is germane to the development of theories of maintenance of avoidance as well as to therapies for the remediation of phobias and hyperanxiety. Baum (1970), after reviewing his and others' data, concluded that a period of response prevention hastened extinction of avoidance. Programming a counterconditioner (an event which, when made contingent on a simple response, is a positive reinforcer) during response prevention is more effective in hastening extinction than is response prevention without counterconditioners (Gordon \& Baum, 1971; Hunsicker, Nelson, \& Reid, 1973; Leclerc, St.-Laurent, \& Baum, 1973: Reid, 1973: Wilson \& Davison, 1971).

The clearest evidence for the efficacy of counterconditioning methods has come from studies in which positive hypothalamic intracranial stimulation (ICS) was used as the counterconditioner (Reid, 1973; Wilson \& Davison, 1971). In addition to demonstrating the efficiency of counterconditioning, the use of ICS provides a convenient way to test different means of programming counterconditioners. This study tested the efficiency of spacing counterconditioning periods within a response prevention period, a procedure analogous to combining counterconditioning (a feature of

*This study was supported by Bradley University's Board for Research, which administers NSF Grant GU 3320. The study is part of a research program codirected by $L$. R eid and Harold $R$. Miller. H. R. Miller is now at Southern Illinois University. We thank Carolyn Reid for assistance. desensitization) and response prevention (flooding or implosion).

\section{METHOD \\ Subjects}

Fifty adult male Sprague-Dawley rats were fixed with chronically indwelling electrodes. The electrodes were bipolar and stainless steel, with the tips aimed for the medial forebrain bundle of the lateral hypothalamus. Histological analyses of nearly all brains confirmed that the site of stimulation was the lateral hypothalamic area.

\section{Apparatus}

ICS was $60-\mathrm{Hz}$ sine waves of $0.25 \mathrm{sec}$, with optimum intensity selected for each $S$ but always from 30 to 70 microA. Footshock of $1.3 \mathrm{~mA}$ was delivered by a Grason-Stadler shock source and scrambler. To prevent possible interaction between ICS and footshock, leads for the two stimulations were never connected simul taneously.

The ledge box has been fully described by Baum (1965). Briefly, it was a box $(30 \times 30 \times 34 \mathrm{~cm})$ with a retractable ledge $17 \mathrm{~cm}$ above the grid. When the ledge was fully in the box, it extended $7 \mathrm{~cm}$ across one side.

\section{Procedure}

After recovery from surgery, Ss were allowed to press a lever in a chamber for ICS. While Ss pressed, ICS intensity was varied. An intensity of ICS was selected that maintained highest rates of pressing without seizures or gross movements. The 10 slowest pressers were eventually used in two groups that received no ICS during treatment; the others were randomly divided into eight groups of five ( $\mathrm{M}$ presses $/ \mathrm{min}=54$ ).

All Ss received the same training. Without habituation to the ledge box, $\mathrm{S}$ was placed on the grid. Ten seconds later, shock came on and stayed on until S got to the ledge. After $30 \mathrm{sec}$ on the ledge, the ledge retracted and returned, beginning a new trial. If $\mathrm{S}$ got to the ledge within $10 \mathrm{sec}$, it avoided shock. This regime continued on the first day of training until $S$ made 10 consecutive avoidances. On each of the following 5 days, $S$ was returned to the box and received 100 trials each day. On the next day, $S$ received a brief shock (about $1 \mathrm{sec}$ ) when first placed into the chamber, and training was continued until $S$ made another 10 consecutive avoidances. Consequently, all Ss received a few more than 520 training trials. At the end of training, footshock was terminated and the ledge was removed from the box for $18 \mathrm{~min}$. during which time one of 10 treatments was programmed.

The study was originally planned for eight treatment groups, but after about one-half of the Ss were tested, it was decided to add two more groups. The first eight groups roughly correspond to a 2 by 4 factorial design with limited vs full response prevention as one factor and spacing of counterconditioners as the other factor. Four groups received a full $18 \mathrm{~min}$ of response prevention, and also received either no ICS or $6 \mathrm{~min}$ of ICS. ICS was limited to either the first, middle, or last $6 \mathrm{~min}$ of the 18 -min period. The other four groups received either no response prevention (no time on grid) or only $6 \mathrm{~min}$ of response prevention. Those receiving $6 \mathrm{~min}$ of response prevention also received ICS during the first, middle, or last part of the $18-\mathrm{min}$ period, i.e., Ss spent a maximum of $6 \mathrm{~min}$ on the grid. These latter four groups spent the time they were not on the grid in a pail next to the chamber. ICS occurred, when programmed, every $2.25 \mathrm{sec}$. The group that spent the full $18 \mathrm{~min}$ in the pail 
Table 1

Trials to Criterion

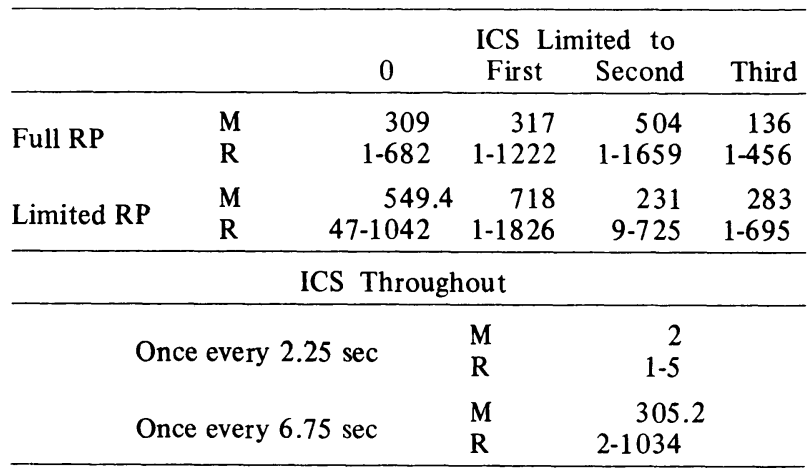

Note-Full $R P$ refers to a condition where $S$ spends entire 18-min treatment period on the grid. Limited RP refers to a condition where $S$ spends a maximum of $6 \mathrm{~min}$ on the grid. $M$ indicates the mean and $R$ indicates the limits of the range.

was the no-treatment control group. The two additional groups spent the entire $18 \mathrm{~min}$ on the grid and received ICS throughout the period; for one group, ICS occurred once every $6.75 \mathrm{sec}$, thus receiving the same number of ICSs as six other groups, and for one other group, ICS occurred once every $2.25 \mathrm{sec}$ for the $18 \mathrm{~min}$, thus receiving three times the ICSs of the other six groups. Because the procedure for one of the groups demanded that Ss be handled four times, all groups were picked up and handled similarly.

After treatments, each $\mathbf{S}$ was placed on the returned ledge. The same program as training was initiated, except without footshock, while the sounds of the shock source continued as before. When $\mathrm{S}$ stayed on the grid for 5 consecutive minutes, all recording equipment was automatically shut off.

The following pretreatment measures were taken: (a) initial body weight, (b) press rates for ICS, (c) trials to first 10 consecutive avoidances, (d) latency of first response in avoidance training, (e) time on grid, (f) time shocked, (g) total trials, and (h) total avoidances.

The following posttreatment measures were taken: (a) trials to criterion, (b) avoidances to criterion, (c) total time on grid until criterion, and (d) latency of first response after treatment. Avoidances and trials to criterion correlate highly (rho $=.99$ ), therefore analysis was performed only on trials.

\section{RESULTS}

Rats took a mean of 27 trials to make 10 consecutive avoidances. On subsequent days, Ss usually took brief shock on the first trial but thereafter avoided. Overall, Ss avoided shock on about $95 \%$ of the trials. On the last day before treatment, rats met the criterion of 10 consecutive avoidances in a mean of 12.5 trials with a range of 10 and 25 trials.

To determine if there were differences that would bias conclusions among the 10 groups prior to their respective treatments, an analysis of variance was performed on each of the pretreatment measures. None of the analyses of the pretreatment measures, except for time on grid and trials to 10 consecutive avoidances on the first day of training, indicated large enough differences to suspect that posttreatment scores might be biased. However, correlations between these values and trials to extinction criterion, perhaps the most meaningful posttreatment measure, were low and insignificant (rhos $=-.20$ and .02 , respectively). Also, Dunnett's test showed that the groups differing reliably from the no-treatment control group on posttreatment scores were not reliably different from the no-treatment control group prior to treatment. It was concluded that rats entered treatment roughly equivalent and that conclusions based on analyses of posttreatment scores, without taking into account pretreatment scores, reflect effects of treatments.

Table 1 provides data of trials to extinction criterion. Factorial analyses of variance on each posttreatment measure of the first eight groups provided little support for the hypothesis of a reliable difference in responsiveness among the eight groups. Only one $\mathrm{F}$ was sufficiently large to indicate a reliable difference: $F$ for factor of limited vs full response prevention time on measure of latency of first response after extinction = 5.4 , df $=1 / 32, p<.05$. Ss spending longer time on the grid took longer to make their first responses following treatment: $\mathrm{M}$ for full response prevention $=145 \mathrm{sec}, \mathrm{M}$ for limited response prevention $=55.8 \mathrm{sec}$. All other Fs were less than 1.5, indicating that spacing of ICS within the 18-min treatment period was not differentially effective and did not interact with amount of response prevention.

Finding little evidence to assume differences among the first eight groups, these eight groups were considered as a single group and were compared to the other two groups with the aid of $t$ tests on each response measure. The group that received ICS once every $6.75 \mathrm{sec}$ was not reliably different from the other eight groups on any measure of response perseveration (ts less than 1.4). Rats receiving ICS once every $2.25 \mathrm{sec}$ did differ reliably from the combined groups $(\mathrm{t}$ for trials $=5.3$, for grid time $=$ 2.9 , for latency of first response $=1.8, \mathrm{df}=43$, ps at or less than .05).

Despite the fact that there is little evidence to support the idea that the no-treatment control group differed from the groups that were combined, it is of interest to compare the additional groups with the no-treatment control group. On all measures of perseveration of responding, the group receiving limited ICS throughout the period showed less perseveration, but only on measures of time on grid and latency of first response were these differences large enough to meet standards of reliability (ts $=2.0,1.9$, respectively). The group with more dense ICS throughout the $18 \mathrm{~min}$ persevered in responding less than the no-treatment control group on all three measures (ts $=11.7,4.1$, and 1.8 for trials, grid time to criterion, and latency of first response, respectively). Data grouped according to amount of treatment, taking into account both length of response prevention and number of ICS during that response prevention, but disregarding the spacing of the ICS, are presented in Fig. 1. In general, Fig. 1 shows that the more treatment, the less perseveration of responding.

\section{DISCUSSION}

The only treatment that dramatically reduced perseveration of 


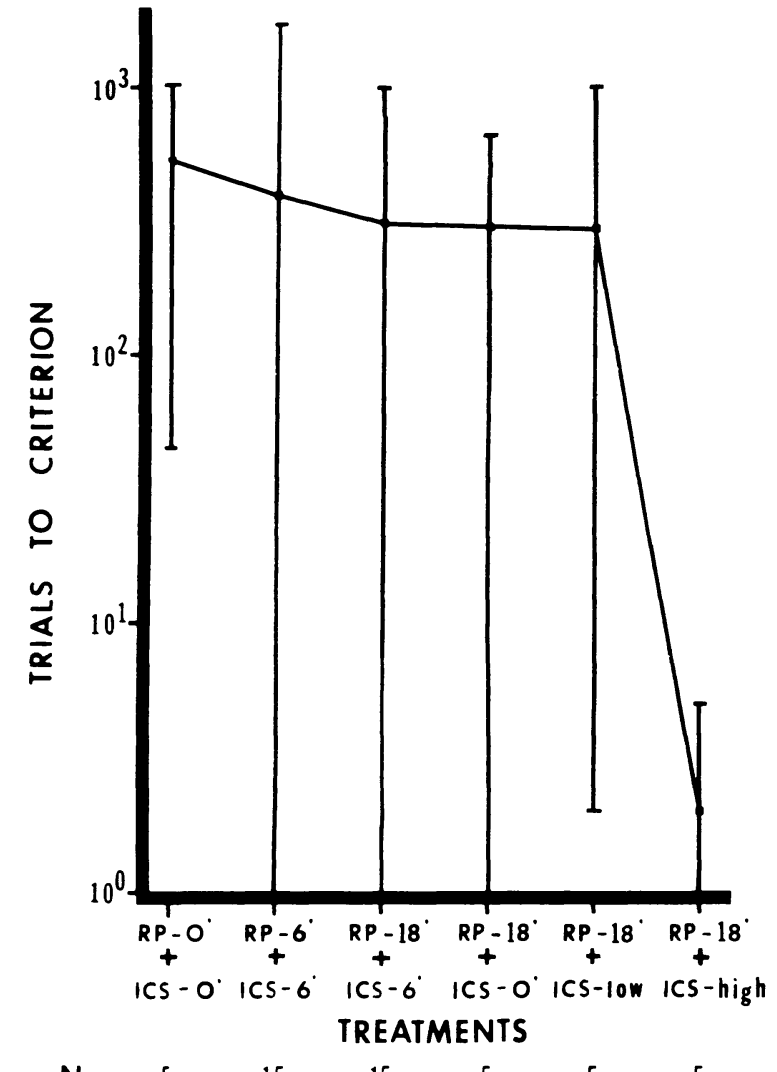

Fig. 1. Mean trials to criterion and range of scores. Number of $\mathrm{SS}$ in each treatment group is shown on the abscissa below each of the treatments.

responding was frequent ICS throughout the longer response prevention period. Because we used small numbers of Ss in each group, there is, however, a danger of concluding that there are no differences. when indeed there are differences among the treatments. If more Ss were tested, the trend in the data that ICS just prior to testing for extinction led to less responding might prove reliable. The achievement of statistically reliable differences among the various groups with differentially spaced counterconditioning, however, would not detract from the conclusion that can be drawn from the data. The combination of response prevention and counterconditioning is surely not more efficient than frequent application of counterconditioners throughout response prevention.

These data, combined with considerable other data of the animal laboratory (e.g., references cited in the introduction), support the conclusion that a counterconditioning procedure is the technique of choice for reducing persisting avoidance, a conclusion that confirms the germinal work of Jones (1924) and Wolpe (1958).

\section{REFERENCES}

Baum, M. An automated apparatus for avoidance training of rats. Psychological Reports, 1965, 16, 1205-1211.

Baum, M. Extinction of avoidance responding through response prevention (flooding) in rats. Psychological Bulletin, 1970, 74, 276-284.

Gordon, A., \& Baum, M. Increased efficacy of flooding (response prevention) in rats through positive intracranial stimulation. Journal of Comparative \& Physiological Psychology, 1971, 75, 68-72.

Hunsicker, J. P., Nelson, T. C., \& Reid, L. D. Two kinds of intracranial stimulation as counterconditioners of persisting intracranial stimulation as counterconditioners of persisting
avoidance in rats. Physiological Psychology, 1973, 1, 227-230. Jones, M. Elimination of children's fears. Journal of Experimental Psychology, 1924, 1, 382-390.

Leclerc, R.. St.-Laurent, J., \& Baum, M. Effects of rewarding, aversive, and neutral intracranial stimulation administered during flooding (response prevention) in rats. Physiological Psychology, 1973, 1, 24-28.

Reid, L. Processes of fear reduction in systematic desensitization: An addendum to Wilson and Davison (1971). Psychological Bulletin, 1973, 79, 107-109.

Wilson, E. T., \& Davison, G. C. Processes of fear reduction in systematic desensitization: Animal studies. Psychological Bulletin, 1971, 76, 1-14.

Wolpe, J. Psychotherapy by reciprocal inhibition. Stanford: Stanford University Press, 1958.

(Received for publication August 24, 1973.)

\section{Preference for reward and nonreward odor trails as a function of reinforcement history*}

\author{
JAMES H. McHOSE \\ Southern Mlinois University at Carbondale \\ Carbondale, Ill. 62901
}

Two hundred and twenty-five rats were tested for preference of reward, nonreward, and neutral odor trails. Rats which had previously received partial or varied reward training showed no preference for reward odor trails, while rats which had previously received continuous reward training preferred reward odor trails. The results were seen to have both methodological and theoretical implications for past and future instrumental conditioning experiments.

In recent years, a number of studies have shown that

*This research was supported by Research Grant NSF GB 30510 from the National Science Foundation. Requests for reprints should be sent to the author at the Department of Psychology, Southern Illinois University at Carbondale, Carbondale, Ill. 62901. the reinforcement event administered to one rat will, under certain circumstances, influence the behavior of another rat in the running order. More specifically, it would appear that rats exude different odors on rewarded $(\mathrm{R})$ as compared with nonrewarded $(\mathrm{N})$ trials and that odors exuded by one $\mathrm{S}$ often perseverated until the next $\mathrm{S}$ in the running order is administered a trial in the same apparatus. One series of studies has demonstrated that the $\mathrm{R}$ and $\mathrm{N}$ odor trails left by one $\mathrm{S}$ can serve as discriminative stimuli for a subsequent $\mathrm{S}$ (e.g., Ludvigson \& Sytsma, 1967; McHose, 1957; Morrison \& Ludvigson, 1970). These data, then, indicate that Ss will learn to respond differentially to $R$ as compared with $\mathrm{N}$ odors when these odors are differentially reinforced. More importantly for present purposes, rats react differentially to reward-related odors even when they are not differentially associated with 